\title{
A Model System to Study Intracellular Trafficking and Processing of the Alzheimer's Amyloid Precursor Protein
}

\author{
Odete A.B. da Cruz e Silva ${ }^{a}$ Sandra Isabel Vieira ${ }^{a}$ Sandra Rebelo ${ }^{a}$ \\ Edgar F. da Cruz e Silva ${ }^{b}$ \\ a Laboratório de Neurociências and 'baboratório de Transdução de Sinais, Centro de Biologia Celular, \\ Universidade de Aveiro, Aveiro, Portugal
}

\begin{abstract}
Key Words
Alzheimer's disease · Amyloid precursor protein · Green fluorescent protein fusion - Protein phosphorylation .

Phosphorylation site mutants · Transfection
\end{abstract}

\begin{abstract}
The occurrence of consensus phosphorylation sites in the intracellular domain of the Alzheimer's amyloid precursor protein (APP), coupled with observations of their in vivo phosphorylation, prompted several workers to investigate the effects that phosphorylation of such sites could have on APP metabolism and subsequent $A \beta$ production. However, hitherto all attempts to dissect the role played by such phosphorylation events failed to reveal substantial effects. Having decided to revisit this problem, our new approach was based on the following vectors: (1) site-directed mutagenesis of the target amino acids to mimic a specific phosphorylation state, (2) expression of wild-type and mutant APP-GFP (green fluorescent protein) fusion proteins for ease of visualization, (3) controlled low level expression to avoid 'flooding' cellular pathways, and (4) the use of cycloheximide to inhibit de novo protein synthesis. Using this method we were able to detect specific differences in APP processing that were correlated with the mimicked phosphorylation state of several phosphorylation sites. New combined methodologies, like the one described here, allow for the
\end{abstract}

detailed analysis of key control points in the cellular metabolism of specific proteins that are central to neurodegenerative diseases and may be under the control of specific posttranslational modifications, such as reversible phosphorylation.

Copyright @ $@ 2004$ S. Karger AG, Basel

\section{Introduction}

The amyloid cascade of Alzheimer's disease is widely accepted as a hypothesis of the molecular basis of this complex multifactorial neurodegenerative disorder [1]. In essence, the theory defends that one of the most important steps in the disease onset and/or development involves the formation and deposition of characteristic cerebral amyloid plaques, whose main constituent is a $4-\mathrm{kD}$ toxic peptide termed $A \beta[2,3]$. In fact, $A \beta$ appears to comprise a heterogeneous mixture of peptides ranging in size from 38 to 44 amino acids. These peptides arise from sequential proteolytic cleavages of the Alzheimer's amyloid precursor protein (APP). This large and ubiquitous protein can exist in various alternatively spliced isoforms $[4,5]$. Although the specific functions of each isoform have not been fully elucidated, of the various known splice variants, APP $_{695}$ (comprising 695 amino acids) is typically referred to as the neuronal isoform, being relatively abundant in the brain [4, 5]. APP can be processed via the secretory pathway, travel-

\begin{tabular}{ll}
\hline KARGER & ( ) 2004 S. Karger AG, Basel \\
Fax +41613061234 & 1660-2854/04/0015-0196\$21.00/0 \\
$\begin{array}{l}\text { E-Mail karger@karger.ch } \\
\text { www.karger.com }\end{array}$ & $\begin{array}{l}\text { Accessible online at: } \\
\text { www.karger.com/ndd }\end{array}$
\end{tabular}

Odete A.B. da Cruz e Silva

Centro de Biologia Celular

Universidade de Aveiro

PT-3810-193 Aveiro (Portugal)

Tel. +351 234370 778, Fax +351 234426 408, E-Mail odetecs@bio.ua.pt 
ing sequentially from the endoplasmic reticulum (ER), through the Golgi network, to the cell surface. It is N-glycosylated [6] and subsequently matures through O-glycosylation upon being transported through the Golgi complex [7]. Once inserted into post-trans Golgi network (post-TGN) secretory vesicles, APP travels to the plasma membrane where it can be cleaved and secreted, or undergoes endocytosis to be recycled or degraded [for review see 8]. Subcellular localization studies indicate that most APP resides in the Golgi complex [9], and in neuronal cells it can also be transported from the cell body down axons by fast axonal transport $[10,11]$.

APP molecules are cleaved during intracellular trafficking, producing various cleavage products, including secreted APP (sAPP), which is released into the medium of cells in culture, and $A \beta$ [12-14]. A small proportion of $\mathrm{A} \beta$ peptides are generated in the ER [15], but the majority is thought to be generated in the Golgi complex [16], packaged into post-TGN vesicles and then secreted extracellularly. Adding to the complexity of $\mathrm{A} \beta$ production, this toxic peptide can also be produced following APP endocytosis from the cell membrane [17].

During the last decade various studies have addressed APP expression, processing and subcellular localization in an attempt to identify factors affecting APP cellular metabolic pathways and to subsequently modulate the rate of $A \beta$ production. Studies have included RT-PCR [18], phosphorylation site mutants [19], in situ hybridization [4], immunocytochemistry [9] and subcellular fractionation [20]. Although extremely informative, such approaches are mostly nondynamic analytical methods that may be insufficient to address alternative APP-processing pathways. Clearly, new approaches are needed to further refine our understanding of APP trafficking, particularly with regard to signal transduction. Recently, Pimpl and Denecke [21] underlined the importance of recent developments in the field of vital fluorescence imaging enabling quantitative protein transport assays and allowing the implementation of in vivo approaches. Indeed, the combination of several methods can be used to unravel protein traffic kinetics and protein interactions. The use of fluorescently tagged proteins, like GFP (green fluorescent protein) translational fusions, provides an extremely powerful tool to address specific protein-trafficking questions. Since protein processing via the secretory pathway involves protein-protein interactions, the introduction of specific alterations in the functional domains of APP may allow us to address the role of the mutated residues in the protein's traffic. Furthermore, protein-protein interactions are highly regulated by protein phosphorylation systems, e.g. binding of APP to the adaptor protein Fe65 [22]. Protein phosphorylationdependent processing of APP has been demonstrated by several groups [22-25]. The production of APP fragments (among them sAPP and A $\beta$ ) appears to be regulated by direct or indirect protein phosphorylation, given that both phorbol esters and protein phosphatase inhibitors significantly increase sAPP secretion and decrease A $\beta$ production [24, 26-29]. Nonetheless, the precise role of protein phosphorylation in APP processing remains to be elucidated. In this paper we describe the development of a dynamic system using a combination of molecular biology, fluorescence imaging, cell culture and biochemical techniques to monitor APP trafficking and to evaluate the effects of mutating potential phosphorylation sites and the modulation of specific signaling pathways.

\section{Methods}

\section{APP-GFP Fusion Constructs}

Point mutations were introduced in specific serine, threonine or tyrosine residues on the APP cytoplasmic domain using site-directed mutagenesis, as previously described [26]. Mutations were introduced into all three signaling domains known to be phosphorylated on the cytoplasmic domain of APP [30]. Serine and threonine residues were mutated to mimic a constitutively phosphorylated site (Glu) or a constitutively dephosphorylated site (Ala), whereas tyrosine residues were mutated to Glu or Phe, respectively [31]. Both wild-type and mutated APP cDNAs were fused in frame with GFP in the pEGFP mammalian expression vector (Clontech, USA) using standard molecular biology techniques. Briefly, APP cDNAs were amplified by polymerase chain reaction using specifically designed primers that removed the stop codon and introduced appropriate restriction sites for ligation into the pEGFP expression vector. All constructs were verified by DNA sequencing to ensure that GFP was fused C-terminally to the APP-coding region and that the required mutations were present.

\section{Cell Culture and Recombinant APP Expression}

Monkey kidney COS-7 cells were grown in Dulbecco's modified Eagle's medium (DMEM) supplemented with $10 \%$ fetal bovine serum at $37^{\circ} \mathrm{C}$ and in an atmosphere of $5 \% \mathrm{CO}_{2} / 95 \%$ air. Cells were normally grown in $100-\mathrm{mm}$ plates at subconfluent conditions before transfection. Cell transfections with both wild-type and mutant APPGFP expression constructs were performed using the LipofectAMINE 2000 (Invitrogen Life Technologies) cationic lipidic transporter. After $8 \mathrm{~h}$, cells were divided into six-well plates with (trafficking studies) or without (processing studies) coverslips pretreated with $100 \mathrm{mg} / \mathrm{ml}$ polyornithine, and allowed to recover for a 4-hour period. For our experimental model, cells were incubated in serum-free DMEM supplemented with $50 \mathrm{mg} / \mathrm{ml}$ cycloheximide (Sigma) to inhibit de novo protein synthesis. At the indicated times, cultures were either fixed in 4\% paraformaldehyde (trafficking studies) or collected as described below (processing studies). The concentration of cycloheximide to be used in the experimental model was assessed in a pilot experiment. Cycloheximide at different concentrations $(15-100 \mathrm{mg} / \mathrm{ml})$ was added to cul- 
tured cells and after $1 \mathrm{~h}$ the levels of intracellular APP were determined by immunoblot analysis, as described below.

\section{Monitoring Intracellular APP-GFP Trafficking by Fluorescence}

Microscopy

After fixation, coverslips were observed using an Olympus IX-81 inverted epifluorescence microscope. Transfected cells were easily identified by the expression of GFP-tagged APP. Cell populations (120 cells/coverslip) were monitored for the presence or absence of fluorescence in specific subcellular compartments, such as the ER, Golgi apparatus, cytoplasmic vesicles, plasma membrane or nucleus. In order to verify the correct identification of the subcellular structures, antibodies against specific marker proteins were used for colocalization studies. For example, anti-calnexin antibodies (Stressgen) were used to mark the ER and anti-syntaxin 6 antibodies (BD Transduction Laboratories) to mark the Golgi network. Subsequent immunodetection was carried out using Texas Red-linked secondary antibodies (Molecular Probes).

Immunoblot Analysis of APP and APP-GFP Processing

In parallel with the protein trafficking assays, the processing of APP-GFP fusion proteins (both wild-type and phosphomutants) was also analyzed by immunobloting. At the specified time points, both cells and conditioned medium were harvested into 1\% SDS and processed as previously reported [32]. Holo-APP was detected by immunoblotting with the anti-APP N-terminal 22C11 antibody (Roche), followed by incubation with a horseradish peroxidase-linked secondary antibody and detection by enhanced chemiluminescence (Amersham Pharmacia). Quantitative analysis of specific immunoreactive proteins was carried out [33] by densitometric analysis of the autoradiograms using Quantity One software (BioRad).

In order to analyze the expression of the different APP isoforms several peripheral tissues and brain regions were dissected, homogenized in 1\% SDS and APP expression was assessed by immunoblotting using the 22C11 antibody. Various cell lines were also tested for APP expression.

\section{Results}

Constitutive phosphorylation of serine, threonine and tyrosine residues can be simulated by mutating those amino acids to glutamate, whereas their constitutive dephosphorylated state can be mimicked by alanine (for serine and threonine) or phenylalanine (for tyrosine). Serine, threonine and tyrosine are amino acids with hydroxyl groups that can be phosphorylated by protein kinases, yielding negatively charged phosphoryl groups (fig. 1). Glutamate and aspartate are nonphosphorylatable amino acids with a carboxylic group whose negative charge and size mimic the presence of the phosphate-negative charge in a phosphorylated amino acid. Alanine and phenylalanine are nonphosphorylatable (lacking the phosphorylatable hydroxyl group) and nonpolar residues that are similar in size to serine/threonine and tyrosine amino acid residues, respectively.
The power of designing specific single or multiple amino acid substitutions in the cytoplasmic domain of APP by site-directed mutagenesis was further extended and refined, by subsequently tagging wild-type and mutant APP with GFP, in order to allow their intracellular localization to be easily tracked. Besides wild-type APP-GFP, several mutant constructs were prepared in the expression vector pEGFP (fig. 2, table 1). Constitutive phosphorylation of Ser655, Thr668, Tyr682 and Tyr687 was mimicked by mutating each to glutamic acid. All expression constructs used the $\mathrm{APP}_{695}$ isoform, which is commonly referred to as the neuronal isoform owing to its relative abundance in brain. In fact, immunoblot analysis of both peripheral tissues and brain regions, and a comparison of nonneuronal cell lines to cells with neuronal characteristics confirmed this assertion (fig. 3). COS-7 cells were chosen for subsequent use since they expressed low levels of the $\mathrm{APP}_{695}$ isoform, can be easily and efficiently transfected and have already been used previously for APPprocessing studies.

Another aspect essential to the success of our model involved optimizing the transfection in order to maintain relatively low levels of recombinant APP expression. The model relies on expressing recombinant APP and endogenous APP at similar levels, thus avoiding overexpression of transfected APP that could result in the saturation of normal cellular pathways. Preliminary studies indicated that since not all constructs exhibited similar transfection efficiencies, the amounts of recombinant APPGFP produced needed to be assessed for each by immunoblot analysis. Since they are relatively easy to transfect and usually exhibit robust expression of recombinant proteins, COS-7 cells were transfected to produce low levels of protein expression. Using the manufacturer's recommended conditions excessively high transfection levels were achieved. Therefore, the amount of recombinant plasmid DNA used in the transfection mixture was reduced to tightly control the production of recombinant protein. Hence, APP-GFP expression levels similar to endogenous APP levels were obtained (fig. 3). In this respect, the B103 cell line may also represent a potentially interesting model. Although previously described as not expressing detectable APP [34, 35], our results clearly indicate that this cell line expresses basal amounts of APP that, although lower than for COS-7 cells, can nonetheless be easily detected (fig. 3d). Quantitative analysis indicated that basal APP levels in B103 are approximately $25 \%$ that of COS-7 cells.

Also critical to the methodology developed was that de novo protein synthesis was inhibited by the addition of
198

Neurodegenerative Dis 2004;1:196-204 da Cruz e Silva/Vieira/Rebelo/

da Cruz e Silva 


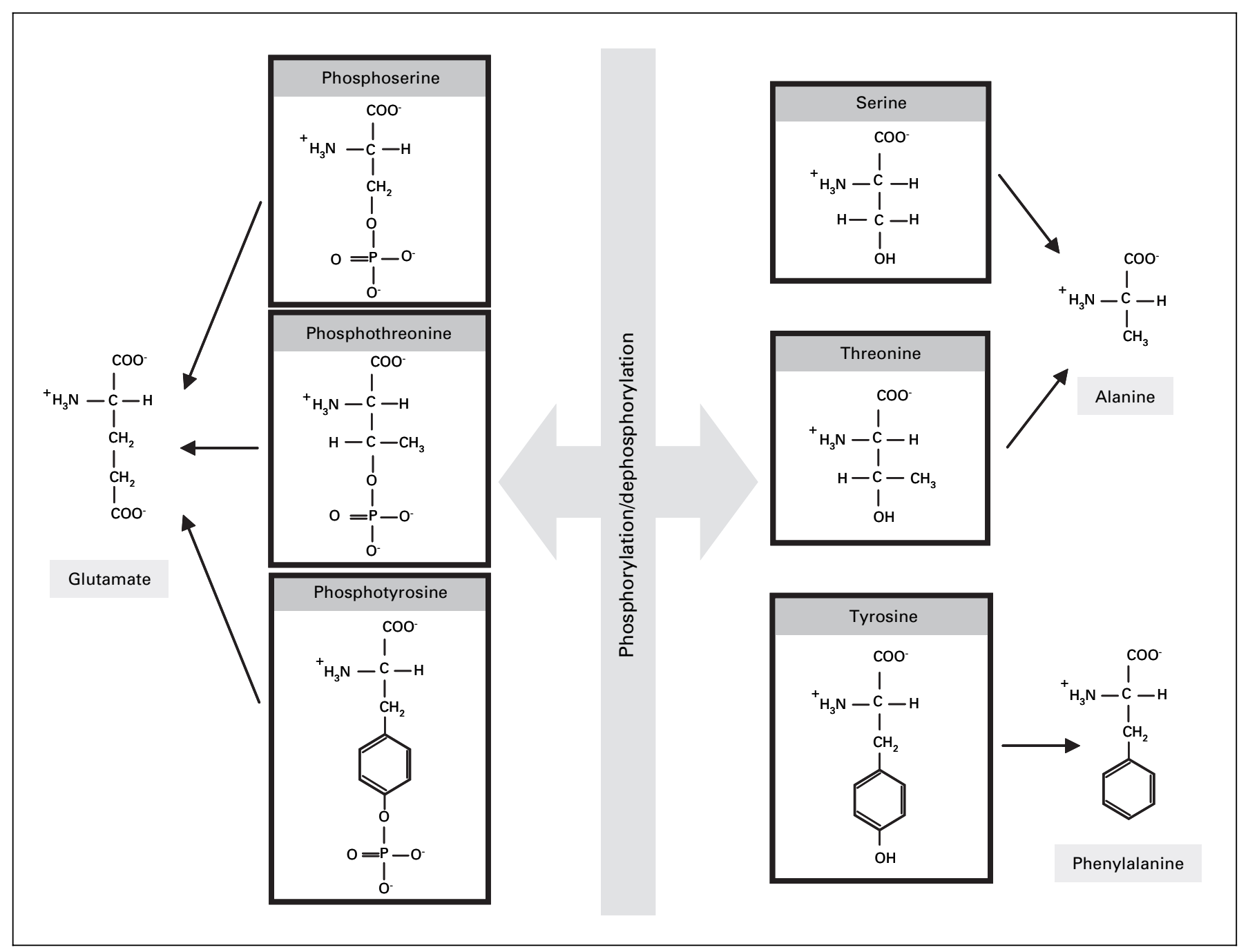

Fig. 1. Comparison of phospho- and dephosphoamino acid structures with their corresponding mutants. Phosphorylated and dephosphorylated serine, threonine and tyrosine residues are shown in boxes. Phosphorylation is catalyzed by protein kinases, whereas dephosphorylation is catalyzed by protein phosphatases. The thin arrows indicate how each amino acid compares with its structural mimic. All mutations were performed by site-directed mutagenesis and confirmed by DNA sequence analysis.

cycloheximide to the culture medium and APP trafficking/degradation was monitored and compared over time. Cycloheximide reversibly inhibits protein synthesis by blocking mRNA translation at the level of polypeptide translocation, without affecting the cellular constitutive secretory pathway, at the concentration and incubation times used [36]. The concentration of cycloheximide chosen for the experimental model was $50 \mathrm{mg} / \mathrm{ml}$, since this concentration produced 60 and $80 \%$ decreases in immunodetectable intracellular APP at 1 and $3 \mathrm{~h}$ (fig. 4, 5a, c), respectively.

A Model System to Study Alzheimer's

Amyloid Precursor Protein
Wild-type $\mathrm{APP}_{695}$-GFP fusion protein appears to be processed and degraded in approximately $4 \mathrm{~h}$ (data not shown) and to follow the expected cellular secretory pathway [9]. Thus, APP-GFP fluorescence was first detected in the ER with a typical perinuclear distribution (fig. 5a, $1 \mathrm{~h}$ ), traveled to and through the Golgi complex as it matured (fig. 5a, 1:00-3:00 h), and was subsequently found in cytoplasmic vesicles (e.g. Golgi secretory vesicles) and the plasma membrane (fig. 5a, 3:00 h). Subcellular localizations were confirmed by colocalization studies with several markers, in particular calnexin and syntaxin 6 which label

Neurodegenerative Dis 2004;1:196-204 
Fig. 2. APP-GFP expression vectors. $\mathrm{APP}_{695}$ wild-type and mutant cDNAs were subcloned into pEGFP to produce the corresponding pAPP-GFP expression vectors. APP and GFP are expressed as in-frame fusion proteins, as shown. The amino acid sequence of the cytoplasmic domain of APP is enlarged below, with the putative phosphorylation sites indicated by asterisks within the three signal transduction domains (larger font in bold). The approximate location of the $A \beta$ sequence is indicated by a black box.

Fig. 3. Comparison of APP expression in different cell lines and tissues. The expression and relative abundance of the different APP isoforms in different tissues and cell lines was assessed by immunoblot analysis (a-d). a Peripheral tissues. $\mathrm{Sm}=$ Skeletal muscle; $\mathrm{Li}=$ liver; $\mathrm{K}=$ kidney; $\mathrm{T}=$ testis; $\mathrm{H}=$ heart; $\mathrm{S}=$ spleen; $\mathrm{Lu}=$ lung. $\mathbf{b}$ Brain regions. $\mathrm{Ce}=$ Cerebellum; $\mathrm{Co}=$ cortex $; \mathrm{St}=$ striatum; $\mathrm{Hp}=$ hippocampus. a, b COS-1 cells are included for comparative purposes. c Untransfected cells, including both nonneuronal cell lines (A431, 3T3) and cell lines with neuronal characteristics (HS683, NG108, GT1-3, NS20Y, HTB11, SH-SY5Y). Human grey matter (HG) was included for comparison. $\mathbf{d}$ Comparison of APP expression in untransfected (U) and wild-type pAPPGFP-transfected (T) nonneuronal COS-1 and COS-7 cells, and neuronal B103 cells. For immunoblot analysis $30 \mu \mathrm{g}$ of total protein was used for the different tissues or cell lysates (a-c), whereas $20 \mu \mathrm{g}$ of total protein were used for COS- 1 and COS-7 cells, and $50 \mu \mathrm{g}$ of total protein were loaded for B103 cells $(\mathbf{d})$. Arrows indicate the migration of the indicated APP isoforms and $i$ and ii indicate transfected $\mathrm{APP}_{695}$-GFP in its immature and mature forms, respectively.
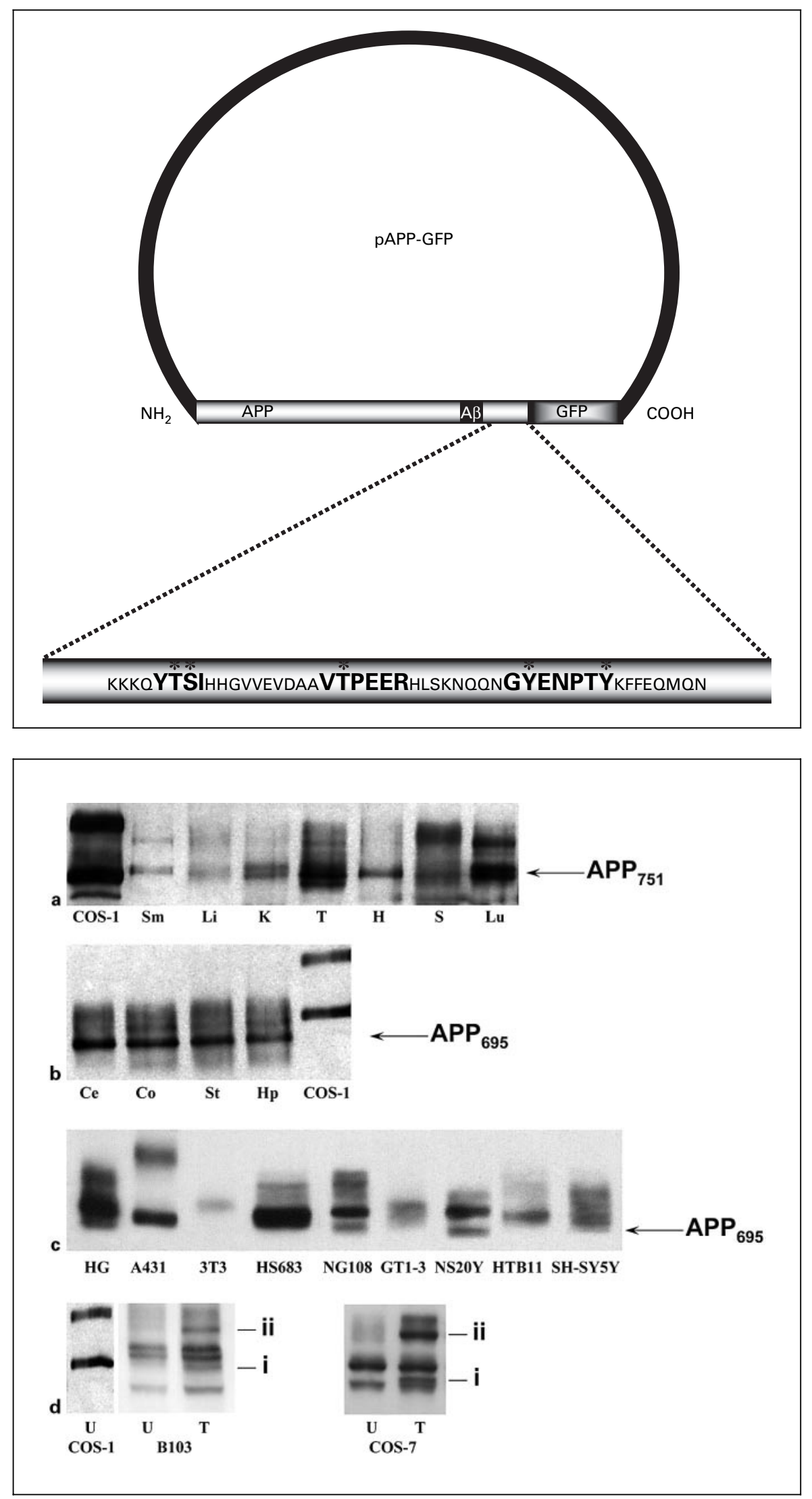


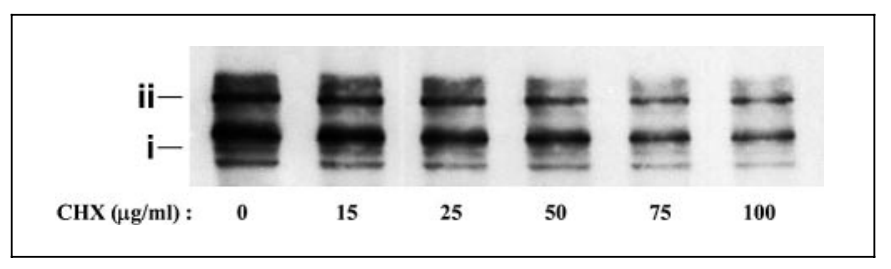

Fig. 4. Effect of increasing cycloheximide concentration on basal APP expression. COS-7 cells were transfected with wild-type pAPPGFP and treated with increasing concentrations of cycloheximide (CHX). Cells were collected for immunoblot analysis after $1 \mathrm{~h}$ and APP expression was analyzed with the $22 \mathrm{C} 11$ antibody. Intact remaining APP was assessed by quantitative densitometric analysis of the blot. $i$ and ii transfected APP-GFP in its immature and mature forms, respectively.

Table 1. List of APP phosphorylation site mutants under study

\begin{tabular}{lll}
\hline Target amino acid & $\begin{array}{l}\text { Constitutive } \\
\text { phosphomutant }\end{array}$ & $\begin{array}{l}\text { Constitutive } \\
\text { dephosphomutant }\end{array}$ \\
\hline Serine 655 & S655E & S655A \\
Threonine 668 & T668E & T668A \\
Tyrosine 682 & Y682E & Y682F \\
Tyrosine 687 & Y687E & Y687F \\
\hline
\end{tabular}

Amino acid numbering according to $\mathrm{APP}_{695}$ isoform.

the ER and TGN, respectively (fig. 5b). Corresponding studies monitoring intracellular and SAPP revealed that wild-type APP-GFP matured and was secreted in a similar manner to endogenous APP (fig. 5c).

Interesting differences between the intracellular trafficking kinetics of wild-type and phosphomutant APP proteins could be observed (fig. 6). Data thus far obtained has elucidated that specific mutations have a direct effect on intracellular APP targeting and its subsequent processing. For example, mimicking constitutive phosphorylation of residues Ser655, Tyr682 and Tyr687 resulted in clear differences in the efficiency of APP incorporation into cytoplasmic vesicles. Whereas the incorporation of the S655E mutant into vesicles was similar to wild-type APP, the Y682E and Y687E mutants were largely absent from cytoplasmic vesicles. Interestingly, constitutive dephosphorylation of the Tyr682 site (Y682F) appears to result in retention of APP in the Golgi (fig. 6). Further experiments are under way to allow a detailed comparison of the processing not only of the mutants described above (table 1), but also of specific double mutants and deletion mutants.

A Model System to Study Alzheimer's

Amyloid Precursor Protein

\section{Discussion}

Recent work from our laboratory has been successful in developing a model system directed at unraveling phosphorylation-dependent APP processing. Prerequisites for studies aimed at clarifying the functional impact of the phosphorylation of specific amino acids necessitate quantitative and stable modification of the target residues. Thus, mimicking constitutive phosphorylation/dephosphorylation allows the in vivo and in vitro evaluation of the functional impact of phosphorylating specific amino acids, without the potential interference of cellular phosphatase and/or kinase activities that may act upon those sites [31]. The inclusion of cycloheximide was particularly useful since it dramatically reduced the background of fluorescent fusion proteins being continuously synthesized. In its presence, since de novo protein synthesis was considerably inhibited, the previously synthesized APP-GFP population was preferentially detected and followed. This drug has been used previously to study the importance of specific posttranslational protein modifications, such as prenylation [37], and the role of protein synthesis in apoptosis [38], gene expression [39] and steroidogenesis [40]. The data presented here were obtained using COS-7 cells, as justified in the Results section. However, for subsequent experimentation, neuronal B 103 cells are also being used, given that they express low levels of APP and provide an attractive model for studying neuronal systems.

The methodology established consisted of the combined usage of site-directed mutagenesis, in-frame fusion with a reporter gene (GFP) in a mammalian expression vector, mammalian cell culture techniques coupled with controlled transfection and expression levels, and inhibition of 'de novo' protein synthesis, thus allowing the monitoring of an APP protein pool in a time-dependent manner by means of fluorescence microscopy and immunoblot analysis (fig. 5). The results obtained (fig. 6) indicate that this new methodology represents an attractive model to study APP metabolism, including not only the tracking of its subcellular localization, traffic and rates of processing and degradation, but also to test the subcellular effects of direct APP phosphorylation.

The usefulness of our model system was entirely validated by the results obtained, since the wild type and the different mutants of the same residue were processed differently with time (fig. 6). Our results lend support to the notion that the phosphorylation state of specific amino acids in the intracellular domain of APP are of paramount importance in deciding its processing and metabolic fate. That is, the exact processing of APP is dependent on the 


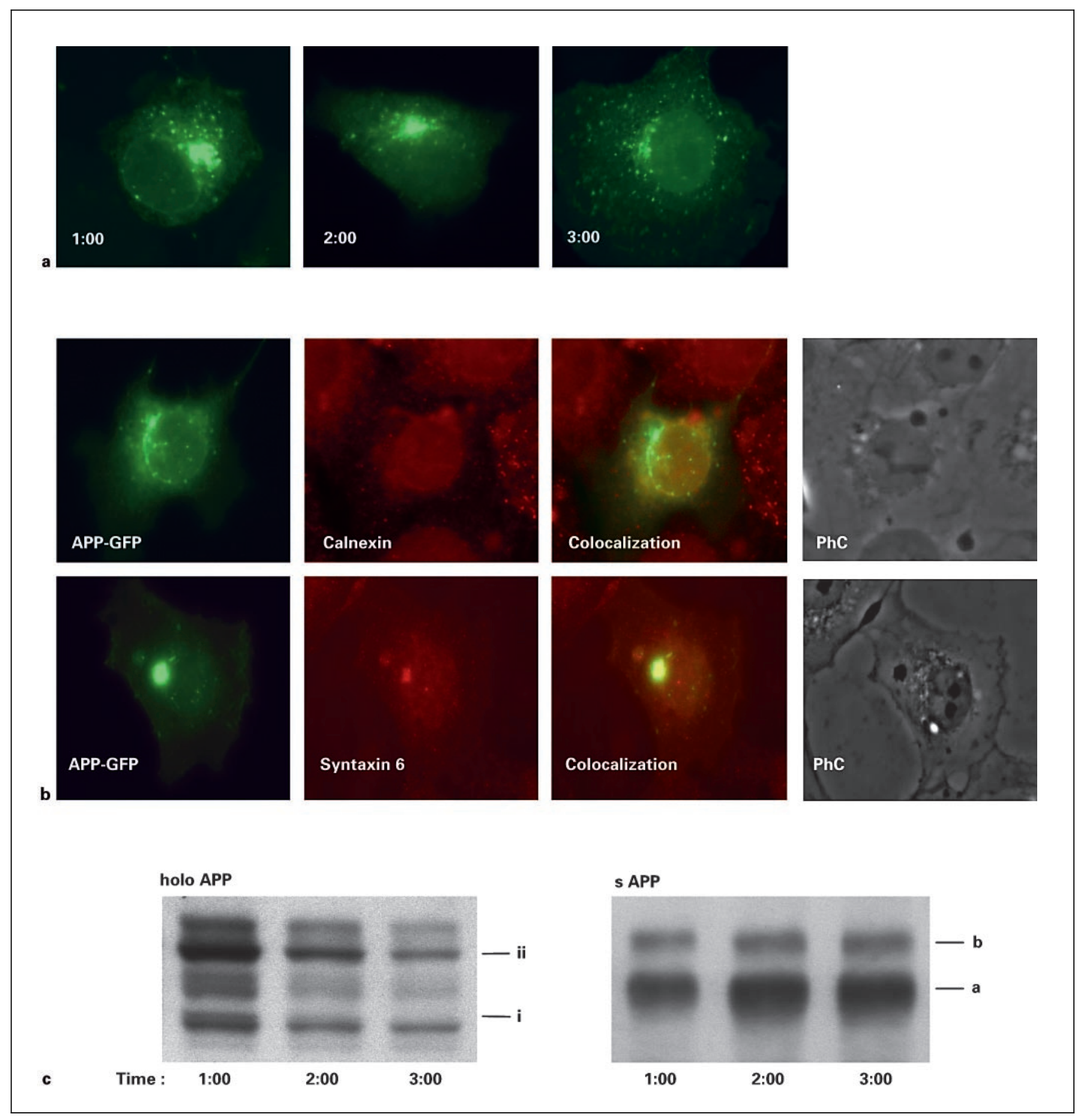

Fig. 5. Fluorescence microscopy analysis of wild-type APP-GFP trafficking in COS-7 cells. a Representative wildtype APP-GFP fluorescence distribution pattern detected after 1, 2 and $3 \mathrm{~h}$ in the presence of cycloheximide. b Colocalization analysis of APP-GFP fusion protein fluorescence and two subcellular compartment markers (calnexin for the ER and syntaxin 6 for the Golgi network) detected by immunocytochemistry with Texas Red-linked secondary antibodies. $\mathrm{PhC}=$ Phase contrast. $\mathbf{c}$ Immunoblot analysis with antibody $22 \mathrm{C} 11$ of the corresponding cell lysates and culture medium for holo-APP-GFP and sAPP, respectively. $i$ and ii transfected APP-GFP in its immature and mature forms, respectively. Secreted sAPP accumulates in the medium: SAPP $_{695}$ mostly derived from transfected pAPP-GFP (a) and endogenous sAPP751/770 (b). 

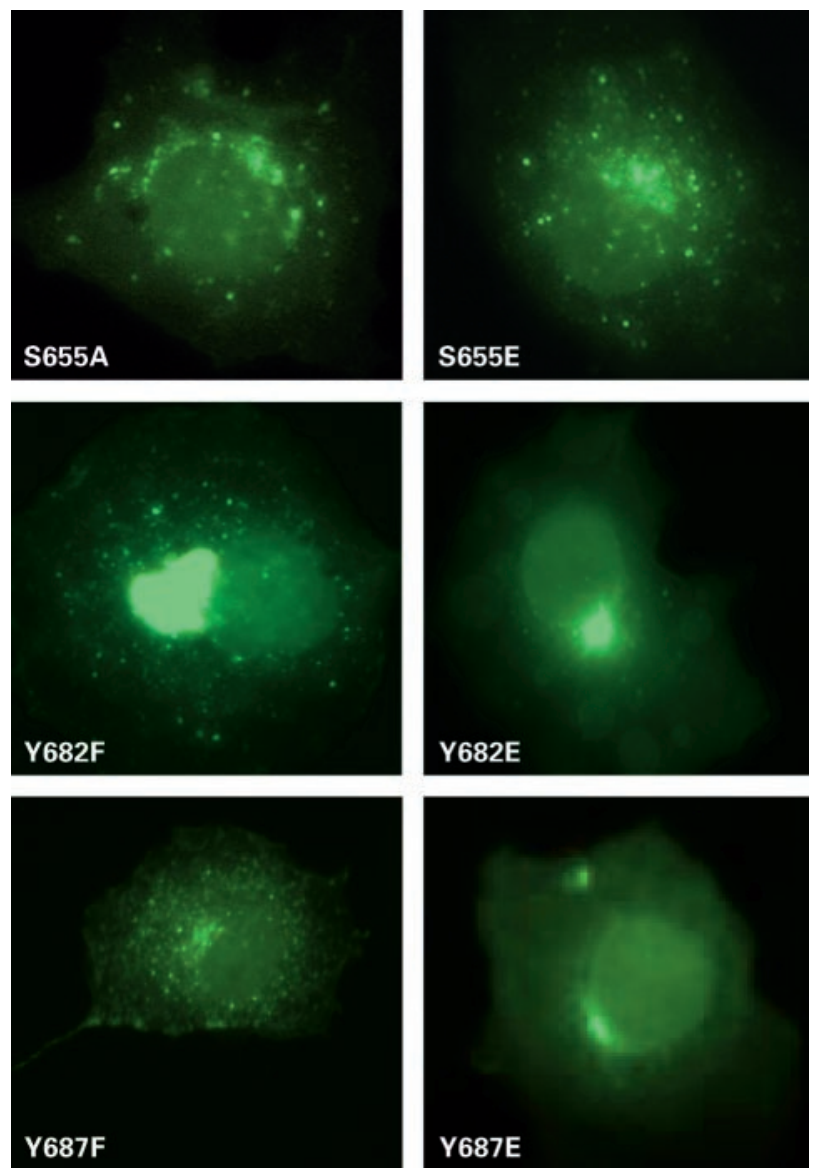

Fig. 6. Comparison of the subcellular localization of different APP-GFP mutants. Representative APP-GFP cell fluorescence distribution patterns for different phosphorylation site mutants after a 3-hour incubation period with cycloheximide. The putative effects of both constitutive phosphorylation (S655E, Y682E and Y687E) and dephosphorylation (S655A, Y682F and $\mathrm{Y} 687 \mathrm{~F}$ ) are clearly observed.

phosphorylation and dephosphorylation of APP itself. The model thus developed not only represents a powerful tool in the study of intracellular protein trafficking, but also provides a useful method for studying the role that some amino acid residues and/or specific posttranslational modifications may have in a protein's intracellular fate. A significantly novel aspect to the method described is provided by the fact that we can mimic a constitutively phosphorylated or dephosphorylated residue and thus dramatically affect APP trafficking. For example, the Y682F mutant is clearly retained in the Golgi, whereas the Y682E mutant is not. This then points to the importance of Y682 phosphorylation for the exit of APP from the Golgi. Additionally, preliminary analysis of the results obtained with the different APP phosphomutants indicates that direct APP phosphorylation may also be important for e.g. incorporation of APP into vesicles. Thus, the overriding aspect is not whether or not a residue is mutated, but rather whether the mutation is mimicking a constitutively phosphorylated or dephosphorylated state. More detailed studies are currently under way to unravel the exact physiological importance of the phosphorylation of the target amino acids in the signaling domains identified within the cytoplasmic tail of APP (fig. 2, table 1), including the production of $A \beta$ itself.

By comparative analysis of the characteristics and relative kinetics of wild-type and mutant proteins, it is possible to unravel the absolute and relative importance of specific amino acid residues, protein domains, or protein interactions, in its targeting and/or in the mechanism itself of protein translocation over the different subcellular compartments towards its final destination within the cell. Of particular note are the recent findings that APP binds to several other proteins which effectively affect its fate. In fact, complex formation is a critical step in signal transduction systems and is highly regulated by protein phosphorylation [30]. Several binding proteins are common in the processing and metabolism of target proteins. The model described here is potentially useful to study different proteins, among them proteins involved in other neurodegenerative disorders. Both Alzheimer's disease and other neurodegenerative disorders are associated with dysfunctional signal transduction pathways and abnormal protein phosphorylation. Hence, it is not surprising to find that signal transduction therapeutics is a rapidly expanding field, potentially providing novel therapeutic strategies for a variety of dysfunctional conditions.

\section{Acknowledgments}

We would like to thank L. Mucke (Gladstone Institute of Neurological Disease, University of California, San Francisco, Calif., USA) for his kind gift of the B103 cell line.

This work was supported by grants to O.A.B.C.S. from the Fundação para a Ciência e Tecnologia of the Portuguese Ministry of Science and Higher Education (POCTI/NSE/33520/1999 and POCTI/BCI/34349/1999) and by the 5th Framework Program of the European Union (Project DIADEM, QLK3-CT-2001-02362). S.I.V. and S.R. were recipients of $\mathrm{PhD}$ fellowships from Fundação para a Ciência e Tecnologia (PRAXIS XXI/BD/16218/98) and from the Instituto de Investigação of the Universidade de Aveiro, respectively. 


\section{References}

1 Hardy J, Selkoe DJ: The amyloid hypothesis of Alzheimer's disease: Progress and problems on the road to therapeutics. Science 2002;297: 353-356.

2 Lee VM-Y: Tauists and baptists united - well almost! Science 2001;293:1446-1447.

-3 Maiorini AF, Gaunt MJ, Jacobsen TM, McKay AE, Waldman LD: Potential novel targets for Alzheimer pharmacotherapy. I. Secretases. J Clin Pharm Ther 2002;27:169-183.

$\checkmark 4$ Rockeinstein EM, McConlogue L, Tan H, Power M, Masliah E, Mucke L: Levels and alternative splicing of amyloid beta protein precursor (APP) transcripts in brains of APP transgenic mice and humans with Alzheimer's disease. J Biol Chem 1995;270:28257-28267.

$\checkmark 5$ Sandbrink R, Masters CL, Beyreuther K: APP gene family. Alternative splicing generates functionally related isoforms. Ann NY Acad Sci 1996;777:281-287.

-6 Oltersdorf T, Ward PJ, Henriksson T, Beattie EC, Neve R, Lieberburg I, Fritz LC: The Alzheimer amyloid precursor protein. Identification of a stable intermediate in the biosynthetic/degradative pathway. J Biol Chem 1990; 265:4492-4497.

7 Griffith LS, Mathes M, Schmitz B: Beta-amyloid precursor protein is modified with $\mathrm{O}$ linked N-acetylglucosamine. J Neurosci Res 1995;41:270-278.

$>8$ Gouras GK: Current theories for the molecular and cellular pathogenesis of the Alzheimer's disease. Exp Rev Mol Med 2001;31:1-11.

>9 Caporaso GL, Takei K, Gandy SE, Matteoli M, Mundigl O, Greengard P, De Camilli P: Morphologic and biochemical analysis of the intracellular trafficking of the Alzheimer beta/A4 amyloid precursor protein. J Neurosci 1994;14: 3122-3138.

10 McLaughlin M, Breen KC: Protein kinase C activation potentiates the rapid secretion of the amyloid precursor protein from rat cortical synaptosomes. J Neurochem 1999;72:273-281.

$\checkmark 11$ Stamer K, Vogel R, Thies E, Mandelkow E, Mandelkow EM: Tau blocks traffic of organelles, neurofilaments, and APP vesicles in neurons and enhances oxidative stress. J Cell Biol 2002;156:1051-1063.

12 Nitsch RM, Slack BE, Farber SA, Borghesani PR, Schulz JG, Kim C, Felder CC, Growdon JH, Wurtman RJ: Receptor-coupled amyloid precursor protein processing. Ann NY Acad Sci 1994;881:122-127.

13 Checler F: Processing of the $\beta$-amyloid precursor protein and its regulation in Alzheimer's disease. J Neurochem 1995;65:1431-1444.

$\checkmark 14$ Selkoe DJ, Yamazaki M, Citron M, Podlisny MB, Koo EH, Teplow DB, Haass C: The role of APP processing and trafficking pathways in the formation of amyloid $\beta$-protein. Ann NY Acad Sci 1996;777:57-64.

15 Cook DG, Forman MS, Sung JC, Leight S, Kolson DL, Iwatsubo T, Lee VM, Doms RW: Alzheimer's Abeta (1-42) is generated in the endoplasmic reticulum/intermediate compartment of NT2N cells. Nat Med 1997;3:1021-1023.
16 Greenfield JP, Tsai J, Gouras GK, Hai B, Thinakaran G, Checler F, Sisodia SS, Greengard $\mathrm{P}, \mathrm{Xu} \mathrm{H}$ : Endoplasmic reticulum and transGolgi network generate distinct populations of Alzheimer beta-amyloid peptides. Proc Natl Acad Sci USA 1999;96:742-747.

17 Pasternak SH, Callahan JW, Mahuran DJ: The role of the endosomal/lysosomal system in amyloid-beta production and the pathophysiology of Alzheimer's disease: Reexamining the spatial paradox from a lysosomal perspective. J Alzheimers Dis 2004;6:53-65.

18 Sandbrink R, Masters CL, Beyreuther K: APP gene family: Unique age-associated changes in splicing of Alzheimer's betaA4-amyloid protein precursor. Neurobiol Dis 1994;1:13-24.

19 Haass C, Koo EH, Capell A, Teplow DB, Selkoe DJ: Polarized sorting of beta-amyloid precursor protein and its proteolytic products in MDCK cells is regulated by two independent signals. J Cell Biol 1995;128:537-547.

20 Xia W, Zhang J, Ostaszewski BL, Kimberly WT, Seubert P, Koo EH, Shen J, Selkoe DJ: Presenilin 1 regulates the processing of betaamyloid precursor protein C-terminal fragments and the generation of amyloid beta-protein in endoplasmic reticulum and Golgi. Biochemistry $1998 ; 37: 16465-16471$.

21 Pimpl P, Denecke J: Protein-protein interactions in the secretory pathway, a growing demand for experimental approaches in vivo. Plant Mol Biol 2002;50:887-902.

22 Ando K, Iijima KI, Elliott JI, Kirino Y, Suzuki $\mathrm{T}$ : Phosphorylation-dependent regulation of the interaction of amyloid precursor protein with Fe65 affects the production of beta-amyloid. J Biol Chem 2001;276:40353-40361.

23 Gillespie SL, Golde TE, Younkin SG: Secretory processing of the Alzheimer amyloid $\beta / \mathrm{A} 4$ protein precursor is increased by protein phosphorylation. Biochem Biophys Res Commun 1992;187:1285-1290.

24 da Cruz e Silva EF, da Cruz e Silva OAB, Zaia CTBV, Greengard P: Inhibition of protein phosphatase 1 stimulates secretion of Alzheimer amyloid precursor protein. Mol Med 1995; 1:535-541.

25 da Cruz e Silva EF, Cruz e Silva OAB: Protein phosphorylation and APP metabolism. Neurochem Res 2003;28:1551-1559.

26 da Cruz e Silva OA, Iverfeldt K, Oltersdorf T, Sinha S, Lieberburg I, Ramabhadran TV, Suzuki T, Sisodia SS, Gandy S, Greengard P: Regulated cleavage of Alzheimer beta-amyloid precursor protein in the absence of the cytoplasmic tail. Neuroscience 1993;57:873-877.

27 Gandy SE, Caporaso GL, Buxbaum JD, da Cruz e Silva O, Iverfeldt K, Nordstedt C, Suzuki T, Czernik AJ, Nairn AC, Greengard P: Protein phosphorylation regulates utilization of processing pathways for Alzheimer beta-A4 amyloid precursor protein. Ann NY Acad Sci 1993;695:117-121.
28 Hung AY, Haass C, Nitsch RM, Qiu WQ, Citron M, Wurtman RJ, Growdon JH, Selkoe DJ: Activation of protein kinase $\mathrm{C}$ inhibits cellular production of the amyloid beta-protein. $\mathrm{J}$ Biol Chem 1993;268:22959-22962.

29 Jacobsen JS, Spruyt MA, Brown AM, Sahasrabudhe SR, Blume AJ, Vitek MP, Muenkel HA, Sonnenberg-Reines J: The release of Alzheimer's disease beta amyloid peptide is reduced by phorbol treatment. J Biol Chem 1994;269: 8376-8382.

30 da Cruz e Silva OAB, Fardilha M, Henriques AG, Rebelo S, Vieira S, da Cruz e Silva EF: Signal transduction therapeutics: Relevance for Alzheimer's disease. J Mol Neurosci 2004;23: 123-142.

31 Bibb JA, da Cruz e Silva EF: Identification of post-translational modification sites by site directed mutagenesis; in Hemmings $\mathrm{HC} \mathrm{Jr}$ (ed): Regulatory Protein Modification. Neuromethods. Totowa, Humana Press, 1997, vol 30, pp 275-307.

32 Rebelo S, Henriques AG, da Cruz e Silva EF, da Cruz e Silva OAB: Effect of cell density on intracellular levels of the Alzheimer's amyloid precursor protein. J Neurosci Res 2004;76: 406-414.

33 Amador FC, Henriques AG, da Cruz e Silva $\mathrm{OAB}$, da Cruz e Silva EF: Monitoring protein phosphatase 1 isoform levels as a marker for cellular stress. Neurotoxicol Teratol 2004;26: 387-395.

34 Schubert D, Behl C: The expression of amyloid $\beta$ protein precursor protects nerve cells from $\beta$ amyloid and glutamate toxicity and alters their interaction with the extracellular matrix. Brain Res 1993;629:275-282.

35 Li HL, Roch JM, Sundsmo M, Otero D, Sisodia S, Thomas R, Saitoh T: Defective neurite extension is caused by a mutation in amyloid beta/A4 (A beta) protein precursor found in familial Alzheimer's disease. J Neurobiol 1997; 32:469-480.

36 Brion C, Miller SG, Moore HP: Regulated and constitutive secretion: Differential effects of protein synthesis arrest on transport of glycosaminoglycan chains to the two secretory pathways. J Biol Chem 1992;267:1477-1483.

37 Parat M-O, Fox P: Palmitoylation of caveolin-1 in endothelial cells is posttranslational but irreversible. J Biol Chem 2001;276:1577615782.

38 Satoh T, Enokido Y, Kubo T, Yamada M, Hatanaka H: Oxygen toxicity induces apoptosis in neuronal cells. Cell Mol Neurobiol 1998; 18:649-666.

39 Lusska A, Wu L, Whitlock JP Jr: Superinduction of CYP1A1 transcription by cycloheximide. Role of the DNA binding site for the liganded Ah receptor. J Biol Chem 1992;267: 15146-15151.

40 Miller WL: Mitochondrial specificity of the early steps in steroidogenesis. J Steroid Biochem Mol Biol 1995;55:607-616. 